\title{
Intravenous Administration of Polyethylene Glycol-Coated (PEGylated) Proteins and PEGylated Adenovirus Elicits an Anti-PEG Immunoglobulin M Response
}

\author{
Taro Shimizu, ${ }^{a}$ Masako Ichihara, ${ }^{a}$ Yasuo Yoshioka ${ }^{b}$ Tatsuhiro Ishida, ${ }^{*, a}$ Shinsaku Nakagawa, ${ }^{b}$ and \\ Hiroshi Kiwada ${ }^{a}$ \\ ${ }^{a}$ Department of Pharmacokinetics and Biopharmaceutics, Subdivision of Biopharmaceutical Sciences, Institute of \\ Health Biosciences, The University of Tokushima; 1-78-1 Sho-machi, Tokushima 770-8505, Japan: and ${ }^{b}$ Department \\ of Biotechnology and Therapeutics, Graduate School of Pharmaceutical Sciences, Osaka University; 1-6 Yamadaoka, \\ Suita, Osaka 565-0871, Japan. Received March 27, 2012; accepted May 7, 2012
}

A single intravenous administration of polyethylene glycol-coated (PEGylated) bovine serum albumin (BSA) and ovalbumin (OVA) elicited an anti-PEG immunoglobulin M (IgM) response, similar to that from PEGylated liposomes, although the administration did not elicit specific neutralizing antibodies to BSA and OVA. A cross-reactivity was observed between anti-PEG IgMs elicited by PEG-BSA and PEGylated liposomes. The anti-PEG IgM level induced by PEGylated proteins (BSA and OVA) reached the maximum at day 5 following intravenous injection. This production pattern was consistent with that induced by PEGylated liposomes. Splenectomy suppressed the anti-PEG IgM response against PEG-BSA and PEGylated liposomes. These observations relating PEG-BSA and PEGylated liposomes indicate that PEGylated proteins might promote the immune responses against PEG with a mechanism similar to that of PEGylated liposomes. In addition, a single intravenous administration of PEGylated adenovirus (PEG-Ad) also elicited an anti-PEG IgM response in a PEG-modification ratio dependent manner. To the best of our knowledge, this is the first report showing that an intravenous administration can elicit an anti-PEG IgM response against PEGylated substances. It appears that anti-PEG IgMs can be produced by the systemic administration of a PEGylated substance and may limit the efficacy of PEGylated substances such as proteins, Ad vector and nanoparticles, due to a cross-reactivity seen in some patients. The immunogenicity of PEGylated substances is usually tested against those very substances, rather than against covalently attached PEG. Our study suggests that the PEG immunogenicity of PEGylated therapeutic agents and particles merits further investigation.

Key words PEGylation; anti-polyethylene glycol immunoglobulin M; adenovirus; liposome

Biomedicines, such as protein $\operatorname{drugs}^{1,2)}$ and nucleic acid drugs, ${ }^{3)}$ have attracted considerable attention due to their high biological activity and specificity against target molecules. However, their application is sometimes limited due to their insufficient clinical effects as a result of susceptibility to destruction by proteolytic or nucleolytic enzymes, a short circulating half-life, low solubility, rapid kidney clearance and propensity to generate neutralizing antibodies. ${ }^{4)}$ Covalent conjugation of polyethylene glycol (PEG) to the biological active molecules, by a process called "PEGylation," is one of the promising strategies being used to overcome these limitations. ${ }^{1-3)}$

PEG is one of the most versatile synthetic polymers and is widely believed to lack immunogenicity and toxicity and shows high solubility in water and in many organic solvents. ${ }^{4,5)}$ For instance, proteins modified with PEG have an increased solubility due to the hydrophilicity of grafted PEG; their destruction by protease and the immune system is decreased due to the steric hindrance of grafted PEG; and, glomerular filtration is decreased due to an increase in the apparent size or hydrodynamic volume of a given protein. ${ }^{6-8)}$ Consequently, the pharmacokinetics of bioactive proteins is improved and thereby the PEGylated proteins become useful for therapy. At present, several PEGylated proteins, such as Adagen ${ }^{\circledR}$ (PEG adenosine deaminase), Oncaspar ${ }^{\circledR}$ (PEGasparaginase), PegIntron ${ }^{\circledR}$ (PEG-interferon $\alpha 2 b$ ), Pegasys ${ }^{\circledR}$ (PEG-interferon $\alpha 2 \mathrm{a})$, Neulasta ${ }^{\mathrm{TM}}$ (PEG-G-CSF), Somavert ${ }^{\mathrm{TM}}$

The authors declare no conflict of interest.
(PEG-hGH), Mircera (PEG-erythropoietin), Cimzia (PEGanti-tumor necrosis factor (TNF) $\alpha$ Fab) and one PEGylated oligonucleotide (Macuge ${ }^{\mathrm{TM}}$, Branched PEG-anti-vascular endothelial growth factor (VEGF) aptamer) have been approved by Food and Drug Administration (FDA). ${ }^{9,10)}$ In addition, the PEGylation of a nanocarrier system, such as liposome, attracts a water shell, resulting in the reduced adsorption of opsonins and thus the recognition of the carrier by the cells of the mononuclear phagocyte system (MPS). ${ }^{11)}$ The PEGylated nanocarriers thus obtained possess long circulation properties, and therefore can accumulate efficiently in solid tumors because of the enhanced vascular permeability and retention (EPR) effect in growing tumors. ${ }^{12)}$ Doxorubicin-encapsulated PEGylated liposome (Doxil ${ }^{\circledR}$ and Caelyx ${ }^{\circledR}$ ) has been approved for use in the treatment of Kaposi's sarcoma and both ovarian and breast cancer. ${ }^{13,14)}$ Furthermore, although still in the preclinical stage, PEGylated adenoviruses (PEG-Ad) have been developed and have shown higher accumulation rates, stronger tumor-suppressive activity, and fewer hepatotoxic side effects than unmodified adenoviruses (Ad). ${ }^{10,15-18)}$

In contrast to the preceding argument, we and others have reported that PEGylated liposomes lose the expected long circulating property when they are injected repeatedly in the same animal (the so-called accelerated blood clearance (ABC) phenomenon). ${ }^{19,20)}$ On the basis of our earlier results, ${ }^{21,22)}$ we proposed the following tentative mechanism for the cause of this phenomenon: anti-PEG IgM, which is produced in the spleen in response to the initial dose, selectively binds to the PEG of the second dose liposomes injected several days later 
and subsequently activates the complement system, and, as a consequence, the liposomes are taken up by the Kupffer cells in the liver. Although it is widely accepted that PEG is nonimmunogenic, our studies suggest the possibility that PEG on the macromolecule acquires immunogenicity and elicits anti-PEG IgM. However, there has been no cross-sectional research on anti-PEG IgM production among different PEGylated substances or particles.

In the present study, therefore, we examined the simple issue of whether PEGylated proteins and Ad elicit an antiPEG IgM response, as PEGylated liposome do. Herein, we show that both PEGylated proteins and PEGylated Ad elicit an anti-PEG IgM following a single intravenous injection. To the best of our knowledge, this is the first report regarding the immunogenicity of PEG that has been covalently attached to proteins and Ad following intravenous administration.

\section{MATERIALS AND METHODS}

Materials Methoxypolyethylene glycol succinimidyl glutarate-2000 or $30000\left(\mathrm{mPEG}_{2000}-\mathrm{SGA}\right.$ or $\left.\mathrm{mPEG}_{30000}-\mathrm{SGA}\right)$, methoxypolyethylene glycol succinimmidyl propionate-5000 or $20000\left(\mathrm{mPEG}_{5000}-\mathrm{SPA}\right.$ or $\left.\mathrm{mPEG}_{20000}-\mathrm{SPA}\right)$, hydrogenated egg phosphatidylcholine (HEPC), and 1,2-distearoyl-snglycero-3-phosphoethanolamine- $n$-methoxy (polyethylene glycol)-2000 (mPEG ${ }_{2000}$-DSPE) were generously donated by NOF (Tokyo, Japan). Cholesterol (Chol) was of analytical grade (Wako Pure Chemical Ind., Ltd., Osaka, Japan). All lipids were used without further purification. All other reagents were of analytical grade.

Preparation of PEGylated Liposome PEGylated liposome, composed of HEPC: $\mathrm{Chol}: \mathrm{mPEG}_{2000}-\mathrm{DSPE}=1.85: 1.0$ : 0.15 (molar ratio), was prepared as previously described. ${ }^{20)}$ Briefly, the lipids were dissolved in chloroform, and after evaporation of the organic solvent, the resultant lipid film was hydrated in $N$-(2-hydroxyethyl)piperazine- $N^{\prime} 2$-ethanesulfonic acid (HEPES) buffered saline (25 mm HEPES, $140 \mathrm{~mm} \mathrm{NaCl}$, $\mathrm{pH}$ 7.4). The liposome was sized by subsequent extrusion through polycarbonate membrane filters (Nuclepore, CA, U.S.A.) with pore sizes of $400,200,100$, and $80 \mathrm{~nm}$. The mean diameter of the prepared liposome was determined by using a NICOMP 370 HPL submicron particle analyzer (Particle Sizing System, CA, U.S.A.) and was $113 \pm 19 \mathrm{~nm}$. The concentration of phospholipids was determined by colorimetric assay. ${ }^{23)}$

Preparation of PEGylated Proteins PEGylated proteins were prepared by adding a 4-50 molar excess of activated PEG to bovine serum albumin (BSA) or ovalbumin (OVA) with gentle stirring according to a previously reported method. ${ }^{8,9)}$ BSA was reacted with $\mathrm{PEG}_{2000^{-}} \mathrm{SGA}$ or $\mathrm{PEG}_{30000^{-}}$ SGA at $37^{\circ} \mathrm{C}$ for $1 \mathrm{~h}$. OVA was reacted with $\mathrm{PEG}_{5000}-\mathrm{SPA}$ or $\mathrm{PEG}_{20000^{-}} \mathrm{SPA}$ at $37^{\circ} \mathrm{C}$ for $30 \mathrm{~min}$. To eliminate unreacted $\mathrm{PEG}$ and protein, the reaction mixture was applied to a $\mathrm{Se}$ phacryl S-400HR (PEG-BSAs) or Superose 12-10/300 GL (PEG-OVAs) (GE healthcare, Chalfont, U.K.) gel filtration column. The fractions containing PEGylated protein were collected and concentrated using an Amicon Ultra centrifugal filter device (Millipore Corp, Bedford, MA, U.S.A.). The approximate molecular weight of each PEGylated protein was estimated by sodium dodecyl sulfate-polyacrylamide gel electrophoresis (SDS-PAGE) according to a previously reported method. ${ }^{8)} \mathrm{PEG}_{2000}$-BSA was $116-200 \mathrm{kDa} ; \mathrm{PEG}_{30000}$-BSA was
$>200 \mathrm{kDa} ; \mathrm{PEG}_{5000}-\mathrm{OVA}$ was $66-97 \mathrm{kDa}$; and, $\mathrm{PEG}_{20000}-\mathrm{OVA}$ was $>200 \mathrm{kDa}$.

Preparation of PEGylated Adenoviruses (Ads) We employed an E1-E3-deleted AD type 5 vector constructed by an improved in vitro ligation method. ${ }^{24,25)}$ PEGylation to the $\mathrm{Ad}$ vector was carried out according to a previously demonstrated method. ${ }^{17)}$ Briefly, Ad was incubated with $\mathrm{mPEG}_{5000}$-SPA or $\mathrm{mPEG}_{20000}$-SPA at molar excesses of 50-, 200-, 800-fold at $37^{\circ} \mathrm{C}$ for $45 \mathrm{~min}$ with gentle stirring to allow modification of the viral lysine residues. The modification ratio of each PEGylated adenovirus (PEG-Ad) was determined by SDSPAGE analysis as described previously. ${ }^{15,16)}$ The ratios were approximately 30,45 and $90 \%$, and were dependent on the PEG amount required to elicit a reaction. The particle size of PEG-Ad was measured using a ZETASIZER 3000HS (Malvern, U.K.) and was approximately $100 \mathrm{~nm}$, irrespective of the modification ratio and size of the PEG.

Animal Experiment Male Wistar rats (250-300g) were purchased from Japan SLC (Shizuoka, Japan). All animal experiments were evaluated and approved by the Animal and Ethics Review Committee of the University of Tokushima. PEGylated liposome, PEGylated protein (PEG-BSA and PEGOVA) and PEG-Ad were intravenously injected into rats at a dose of $0.0002 \mu \mathrm{mol}$ phospholipids/animal, $1 \mu \mathrm{g}$ protein/animal, and $10^{11}$ particles/animal, respectively. At indicated days after administration, blood samples were collected from each rat. To obtain serum, the blood was centrifuged at $3000 \mathrm{rpm}$ and $4^{\circ} \mathrm{C}$ for $15 \mathrm{~min}$. To study the effect of the spleen on the anti-PEG IgM response against PEGylated materials, a splenectomy (removal of spleen) was performed as previously described. ${ }^{21)}$ The level of anti-PEG IgM in serum was determined by enzyme-linked immunosorbent assay as described below.

Enzyme-Linked Immunosorbent Assay Each well of the 96-well microtiter plate was coated with $10 \mathrm{nmol}$ of PEGDSPE or $1 \mu \mathrm{g}$ of PEG-BSA by incubation for $2 \mathrm{~h}$. The coated plate was washed 3 times with wash solution $(50 \mathrm{~mm}$ Tris, $0.14 \mathrm{M} \mathrm{NaCl}, 0.05 \%$ Tween 20$)$. Then blocking buffer $(50 \mathrm{~mm}$ Tris, $0.14 \mathrm{M} \mathrm{NaCl}, 1 \% \mathrm{BSA}$ ) was added and incubated for $1 \mathrm{~h}$. After 3 cycles with the wash solution, the diluted sample sera in the sample buffer (50 mu Tris, $0.14 \mathrm{M} \mathrm{NaCl}, 1 \% \mathrm{BSA}, 0.05 \%$ Tween 20) were added and incubated for $1 \mathrm{~h}$. Then, the plate was washed 5 times with wash solution. Horseradish peroxidase-conjugated antibody (goat anti-mouse immunoglobulin M (IgM) IgG-horseradish peroxidase (HRP) conjugate; Bethyl Laboratories, TX, U.S.A.) was added and incubated for a further $1 \mathrm{~h}$. The plate was washed 5 times with wash solution, and then incubated for $5-15 \mathrm{~min}$ followed by the addition of $o$-phenylene diamine (Sigma, MO, U.S.A.). The reaction was stopped by adding $2 \mathrm{M} \mathrm{H}_{2} \mathrm{SO}_{4}$. Absorbance at $490 \mathrm{~nm}$ was measured with a Microplate reader (Wallac1420 ARVOsx, PerkinElmer Life Science).

$\mathbf{C H}_{50}$ Measurement To determine whether the PEGylated materials activate the serum complement system, the residual serum complement activity was measured by functional complement assay $\left(\mathrm{CH}_{50}\right)$ following the incubation of serum with various PEGylated materials. $\mathrm{CH}_{50}$ was determined according to the method described previously ${ }^{22)}$ with sheep red blood cells sensitized with monoclonal anti-sheep IgM antibody (SRBC) $\left(\mathrm{CH}_{50}\right.$ SEIKEN, DENKA SEIKEN, Tokyo, Japan). Briefly, $90 \mu \mathrm{L}$ of rat serum was collected from 


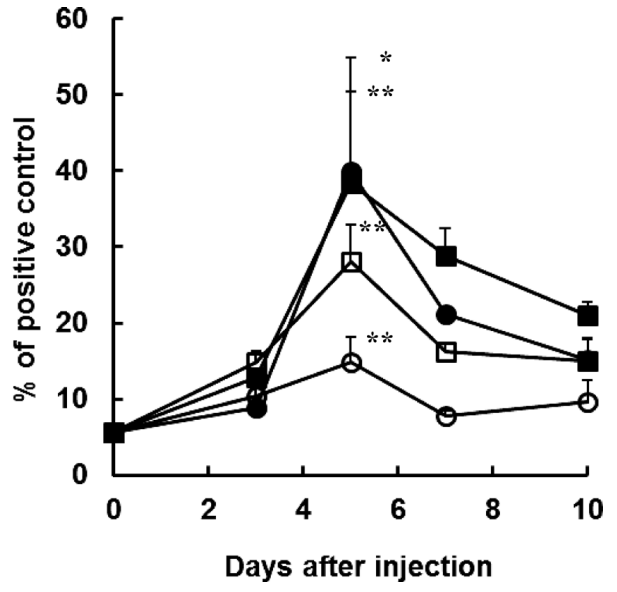

Fig. 1. Anti-PEG IgM Response to PEGylated Proteins

PEGylated proteins ( $1 \mu \mathrm{g} / \mathrm{rat})$ were intravenously injected into rats. At day 3,5 , 7 , and 10 , sera were collected from the rats, and anti-PEG IgM in the sera was determined by ELISA using $\mathrm{mPEG}_{2000}$-DSPE coated 96-well plates. Positive control represents the anti-PEG IgM level elicited by intravenous injection of PEGylated liposome $(0.0002 \mu \mathrm{mol}$ phospholipids/animal $)$ at day 5. Each value represents the mean \pm S.D. $(n=3)$. Open circle, $\mathrm{PEG}_{2000}-\mathrm{BSA}$; Closed circle, $\mathrm{PEG}_{30000}-\mathrm{BSA}$; Open square, $\mathrm{PEG}_{5000}$-OVA; Closed square, $\mathrm{PEG}_{20000}$-OVA. ${ }^{*} p<0.05$ and $* * p<0.01 \mathrm{vs}$. the titer of anti-PEG IgM at day 0.

rats that had received an intravenous injection of PEG-BSAs ( $1 \mu \mathrm{g}$ protein/animal), PEGylated liposome $(0.0002 \mu \mathrm{mol}$ phospholipids/animal) or HEPES. The serum then was incubated with PEGylated liposome or PEG-BSA at $37^{\circ} \mathrm{C}$ for $15 \mathrm{~min}$. Then, $10 \mu \mathrm{L}$ aliquots of the treated serum was diluted with $1 \mathrm{~mL}$ of veronal-buffered saline (VBS; $150 \mathrm{~mm} \mathrm{NaCl}, 75 \mathrm{~mm}$ sodium barbital, $0.15 \mathrm{~mm} \mathrm{CaCl}_{2}, 1 \mathrm{~mm} \mathrm{MgCl}_{2}, 5 \%$ D-glucose, $0.1 \%$ gelatin $\left(\mathrm{DGVB}^{2+}\right)$. Then, $0.4 \mathrm{~mL}$ of SRBC $\left(5 \times 10^{8} / \mathrm{mL}\right)$ was mixed with $2.6 \mathrm{~mL}$ of sequentially further diluted PEGylated materials-treated serum and incubated at $37^{\circ} \mathrm{C}$ for $1 \mathrm{~h}$. Unlysed SRBC were pelleted by centrifugation $(2000 \mathrm{rpm}$, $10 \mathrm{~min}, 4^{\circ} \mathrm{C}$ ) and the amount of hemoglobin released into the supernatant was quantified spectrophotometrically at $541 \mathrm{~nm}$ (UV-1600, Shimadzu, Kyoto, Japan). The $\mathrm{CH}_{50}$ was calculated according to the equations recommended by the manufacturer. The residual complement activity was calculated by dividing the $\mathrm{CH}_{50}$ value in the liposome-treated sample by that in naïve serum.

Statistics All mean values are expressed as the mean \pm S.D. Statistical analysis was performed with a two-tailed unpaired $t$-test and a one-way analysis of variance (ANOVA) using GraphPad InStat software (GraphPad Software, CA, U.S.A.). The level of significance was set at $p<0.05$.

\section{RESULTS}

Anti-PEG IgM Response to PEGylated Proteins Following a single intravenous injection of either $\mathrm{PEG}_{2000}$-BSA, $\mathrm{PEG}_{30000}$-BSA, $\mathrm{PEG}_{5000}$-OVA or $\mathrm{PEG}_{20000}$-OVA, serum antiPEG IgM level was determined with a $\mathrm{mPEG}_{2000}$-DSPE coating plate at indicated time points. As shown in Fig. 1, regardless of the type of protein and chain length of modified PEG, all PEGylated proteins induced anti-PEG IgM production. The serum anti-PEG IgM level began to increase at day 3, reached the maximum at day 5, and then decreased gradually. The level of anti-PEG IgM response was correlated to the length of the PEG chain attached to proteins under our experimental

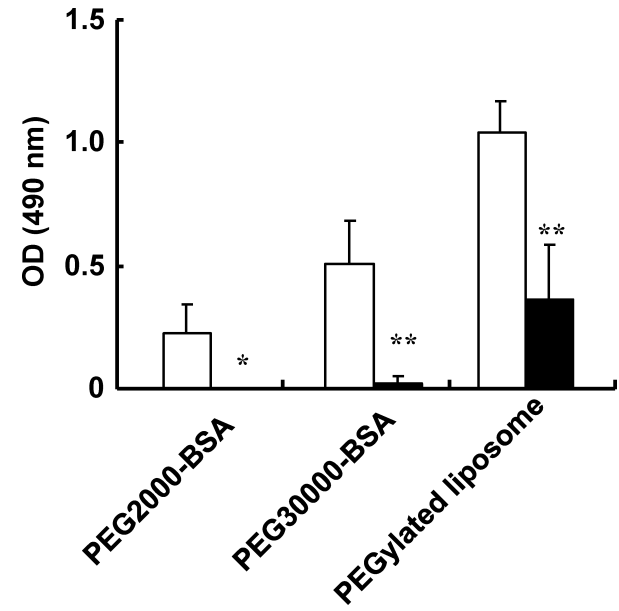

Fig. 2. Anti-PEG IgM Response to PEG-BSAs in Splenectomized Rats

The spleen was removed from rats $7 \mathrm{~d}$ before intravenous injection of either $\mathrm{PEG}_{2000}$-BSA $(1 \mu \mathrm{g} / \mathrm{animal}), \mathrm{PEG}_{30000}$-BSA $(1 \mu \mathrm{g} / \mathrm{animal})$ or PEGylated liposome $(0.0002 \mu \mathrm{mol}$ phospholipids/animal). At day 5 after the injection, anti-PEG IgM in the serum was determined by ELISA using $\mathrm{mPEG}_{2000}$-DSPE-coated plate. Open column represents control (sham-operated) animal. Closed column represents splenectomized animal. Each value represents the mean \pm S.D. $(n=3) .{ }^{*} p<0.05$ and $* * p<0.01 v s$. the anti-PEG IgM production in non-splenectomized (sham-operated) rats.

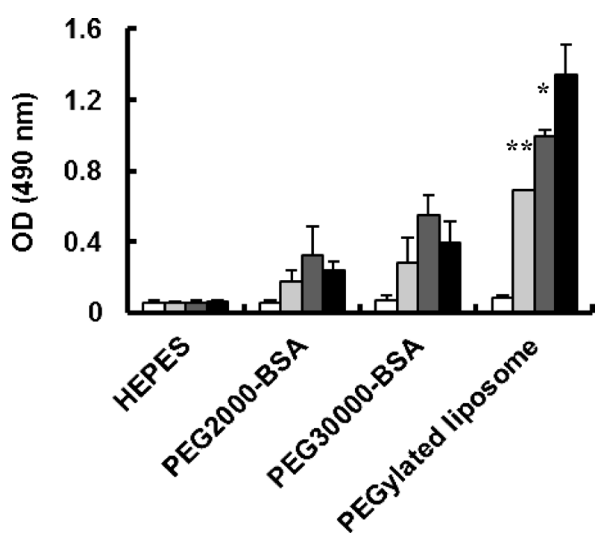

Fig. 3. Cross-Reactivity of Anti-PEG IgM Induced by PEG-BSAs and PEGylated Liposome

The cross-reactivity of anti-PEG IgM induced by either PEG $_{2000}$-BSA $(1 \mu \mathrm{g} / \mathrm{ani}$ mal), $\mathrm{PEG}_{30000}$-BSA $(1 \mu \mathrm{g} / \mathrm{animal})$ or PEGylated liposome $(0.0002 \mu \mathrm{mol}$ phospholipids/animal) was determined by ELISA using 96-well plates coated with either BSA (open column), $\mathrm{PEG}_{2000}$-BSA (light gray column), $\mathrm{PEG}_{30000}$-BSA (dark gray column) or $\mathrm{mPEG}_{2000}$-DSPE (closed column). Each value represents the mean \pm S.D. $(n=2-3) .{ }^{*} p<0.05$ and $* * p<0.01 v s$. the OD in $\mathrm{mPEG}_{2000}-\mathrm{DSPE}$ coated wells.

condition.

Anti-PEG IgM Response in Splenectomized Rats To investigate the contribution of the spleen to the anti-PEG IgM response to PEGylated protein, a splenectomy (removal of spleen) was carried out $7 \mathrm{~d}$ before the intravenous injection of either PEG-BSAs ( $\mathrm{PEG}_{2000}-\mathrm{BSA}$ and $\left.\mathrm{PEG}_{30000}-\mathrm{BSA}\right)$ or PEGylated liposome (positive control). At day 5 after the injection, anti-PEG IgM in the serum was determined with a $\mathrm{mPEG}_{2000}$-DSPE coating plate (Fig. 2). Splenectomy suppressed anti-PEG IgM production against $\mathrm{PEG}_{2000}-\mathrm{BSA}$ and $\mathrm{PEG}_{30000}$-BSA as well as against PEGylated liposome. It appears that the spleen is the major organ that secretes anti-PEG IgM against PEG-BSAs ( $\mathrm{PEG}_{2000}-\mathrm{BSA}$ and $\left.\mathrm{PEG}_{30000}-\mathrm{BSA}\right)$.

Cross-Reaction of Anti-PEG IgM with PEGylated Liposome and PEGylated Protein To characterize anti-PEG 
IgM induced by PEG-BSAs ( $\mathrm{PEG}_{2000}-\mathrm{BSA}$ and $\left.\mathrm{PEG}_{30000}-\mathrm{BSA}\right)$ and PEGylated liposome, the cross-reactivity of anti-PEG IgM induced by one of the PEGylated derivatives to each PEGylated derivative $\left(\mathrm{PEG}_{2000^{-}} \mathrm{BSA}, \mathrm{PEG}_{30000^{-}} \mathrm{BSA}\right.$ or $\mathrm{mPEG}_{2000^{-}}$ DSPE) (Fig. 3). Anti-PEG IgM elicited by $\mathrm{PEG}_{2000}-\mathrm{BSA}$ showed reactivity similar to $\mathrm{PEG}_{2000}-\mathrm{BSA}, \mathrm{PEG}_{30000}-\mathrm{BSA}$, and $\mathrm{mPEG}_{2000}$-DSPE. Anti-PEG IgM elicited by $\mathrm{PEG}_{30000}$-BSA also showed similar reactivity to $\mathrm{PEG}_{2000}-\mathrm{BSA}, \mathrm{PEG}_{30000}$-BSA, and $\mathrm{mPEG}_{2000}$-DSPE. The anti-PEG IgM elicited by PEGylated liposome modified with $\mathrm{mPEG}_{2000}$-DSPE showed higher reactivity to $\mathrm{mPEG}_{2000}$-DSPE than to PEG-BSAs. Interestingly, PEG-BSAs induced no IgM response to BSA at day 5 after the intravenous injection of PEGylated BSA.

Anti-PEG IgM-Mediated Complement Activation The residual complement activity in the serum containing antiPEG IgM was estimated as an indication of anti-PEG IgMmediated complement activation by the PEGylated substances. The complement activity in the sera following incubation with various PEGylated substances $\left(\mathrm{PEG}_{2000}-\mathrm{BSA}, \mathrm{PEG}_{30000}-\mathrm{BSA}\right.$ and PEGylated liposome) was determined using a $\mathrm{CH}_{50}$ assay kit (Fig. 4). The complement activity in the HEPES-treated sera from the rats that received each PEGylated material was set at $100 \%$. No PEGylated substances consumed complement in the sera from the rats that had received HEPES. Also, in the sera from the rats that had received $\mathrm{PEG}_{2000}$-BSA, no consumption was induced by incubation with PEGylated substances. To the contrary, in the sera of the rats that had received $\mathrm{PEG}_{30000}$-BSA, significant consumption was induced by incubation with $\mathrm{PEG}_{30000}$-BSA and PEGylated liposome. Interestingly, in the sera from rats that had received PEGylated liposome, only PEGylated liposome consumed the complement, but other PEGylated substances were hardly consumed.

Anti-PEG IgM Response to PEGylated ADs In order to improve the resident time in the blood and attenuate immunogenicity, PEGylation has been preferentially attempted with a virus vector such as Ad. ${ }^{15-18)}$ We investigated whether PEG-Ad elicits an anti-PEG IgM response similar to PEG-proteins and PEGylated liposome as described above. All PEG-Ads used in this study obviously induced an anti-PEG IgM response at day 5 after a single intravenous injection (Fig. 5). The PEGmodification ratio of Ad strongly affected the level of antiPEG IgM production. Both $\mathrm{PEG}_{5000}$-Ad (45\%) and $\mathrm{PEG}_{20000^{-}}$ Ad $(45 \%)$ induced a significantly higher response than other PEG-Ads with different modification ratios $(30 \%$ or $90 \%)$. The levels of anti-PEG IgM response elicited by $\mathrm{PEG}_{5000}$-Ad $(45 \%)$ and $\mathrm{PEG}_{20000}$-Ad (45\%) were comparable to that by PEGylated liposomes (positive control). It appeared that the chain length of PEG promotes the anti-PEG IgM response against PEG-Ad.

\section{DISCUSSION}

In the present study, we showed that PEG-proteins (PEGBSA and PEG-OVA) and PEG-Ad induce an anti-PEG IgM response, as PEGylated liposomes do, following a single intravenous injection (Figs. 1, 5). This is a surprising result because PEG conjugates are widely regarded as having low immunogenicity and being immunologically safe., ${ }^{926)}$ Hence, PEGylation technology successfully generated several FDAapproved proteinous and nucleic substances and nanocarriers that are considered non immunogenic, and the technology continuously applies to new substances such as nucleic acids,

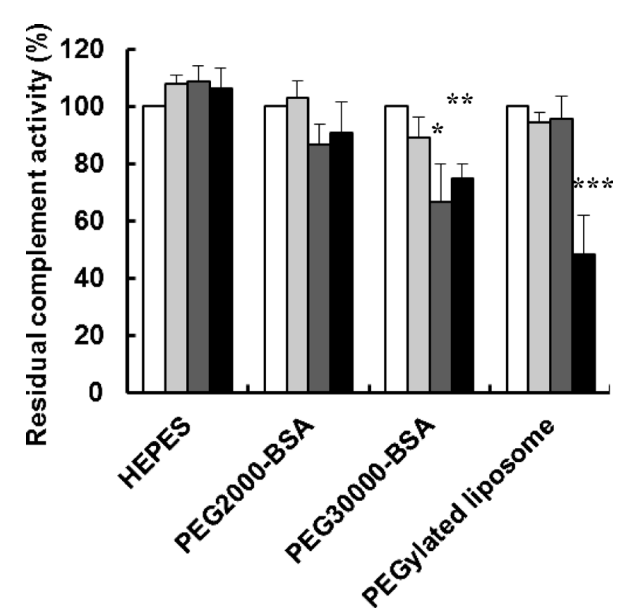

Fig. 4. Anti-PEG IgM-Mediated Complements Activation

To obtain the sera containing anti-PEG IgM, PEG-BSAs or PEGylated liposome, each was intravenously injected into rats. At day 5 , the sera were collected. The sera were incubated with HEPES (open column), $\mathrm{PEG}_{2000}$-BSA (light gray column), $\mathrm{PEG}_{30000}$-BSA (dark gray column) or PEGylated liposome (closed column) to consume the complement. Residual complement activity in the treated sera was assayed using a $\mathrm{CH}_{50}$ kit. Each value represents the mean \pm S.D. $(n=3) . * p<0.05$, $* * p<0.01, * * * p<0.001 v$ s. HEPES-treated sera (open column, negative control)

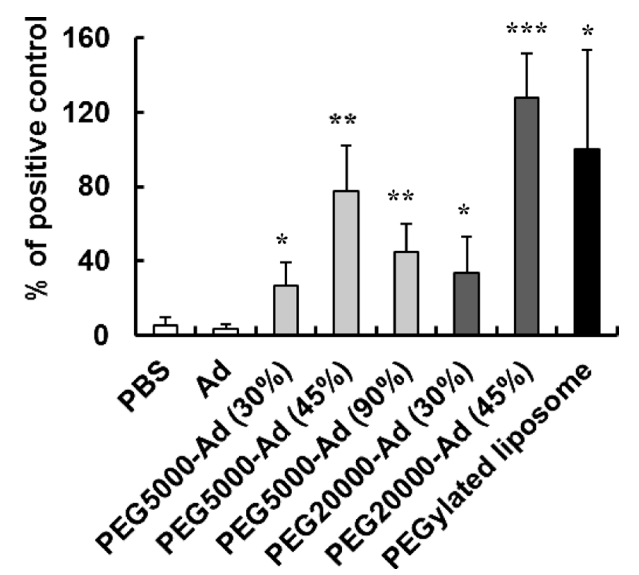

Fig. 5. Anti-PEG IgM Response to PEG-Ad

Various PEG-Ads ( $10^{11}$ particles/animal) were intravenously injected into rats. Five days later, anti-PEG IgM in the sera was determined by ELISA with mPEG $_{2000}$-DSPE-coated 96-well plates. Positive control represents the amount of anti-PEG IgM elicited by PEGylated liposome $(0.0002 \mu \mathrm{mol}$ phospholipids/animal $)$ Each value represents the mean \pm S.D. $(n=4) .{ }^{*} p<0.05, * * p<0.01, * * * p<0.001 v s$. PBS

several nanocarriers and viral vectors. ${ }^{3,10)}$ However, our results clearly indicate that the covalent coupling of PEG to substances results in either the loss or the masking of the original antigenicity and immunogenicity as expected, but also results in the appearance of the antigenicity and immunogenicity of PEG, neither of which has ever been shown by the intravenous injection of PEG itself.

There were several reports relating anti-PEG antibody responses against PEGylated proteins and PEG itself. It must be noted that such immunological responses were entirely promoted by subcutaneous administration, and not by intravenous administration. Richter and Akerblom ${ }^{27)}$ showed that the subcutaneous administration of PEG (5900 Da) to mice would elicit a weak and transitory immune response to PEG. They also showed a stronger anti-PEG immune response to PEGOVA subcutaneously administered with Freund's complete 
adjuvant. In addition, Ganson et al. ${ }^{28)}$ reported that anti-PEG antibody was elicited in a phase I trial of subcutaneous PEGylated urate oxidase. A similar response to PEG has been observed in patients receiving intramuscular administration of FDA-approved Oncaspar ${ }^{\circledR}$ (PEG-asparaginase). ${ }^{29)}$ In the current study, we showed that a single intravenous injection of PEG-proteins will elicit an anti-PEG IgM response (Fig. 1). This suggests that the intravenous administration of PEGylated proteins is clinically recommended, but it may induce an immunological response to PEG grafted to the proteinous subjects. To the best of our knowledge, this is the first report showing an immunological response to PEG following intravenous administration with PEGylated proteins.

In the present study, we employed BSA and OVA as test proteins which are exogenous proteins to mouse. There is a possibility that such exogenous proteins covalently attached to PEG might induce anti-PEG IgM response. Rubin ${ }^{30)}$ have reported that haptenized endogenous protein induces anti-hapten antibody, as haptenized exogenous protein does. Klaus et al. $^{31)}$ studied on the immunological properties of haptens coupled to thymus-independent (TI) carrier molecules and showed that the carrier need not be immunogenic for the induction of anti-hapten antibody responses. There seems no difference upon production of anti-hapten antibody such as anti-PEG response between exogenous proteins and endogenous proteins, although further study to prove must be required.

It is easy to be concerned that the presence of elicited antiPEG IgM in blood circulation would affect the pharmacokinetics of a subsequent dose of PEGylated substances. We have previously shown that the anti-PEG IgM elicited by the initial dose of PEGylated liposome is responsible for an enhanced clearance of the subsequent dose as a result of complement activation. $^{22,32)}$ A similar phenomenon was observed in PEGmodified poly lactide (PLA)-nanoparticles ${ }^{33)}$ and in PEG-modified micelles. ${ }^{34)}$ Roffler and co-workers ${ }^{35,36)}$ have generated anti-PEG IgM monoclonal antibody by immunization with an antibody-PEG-modified $\beta$-glucronidase $(\beta \mathrm{G})$ and have shown that when intravenously injected the generated anti-PEG IgM induced an accelerated clearance of PEG-modified $\beta \mathrm{G}$ from blood circulation. Our current study demonstrated that the elicited anti-PEG IgM has a cross-reactivity between PEG grafted onto proteins and PEG on nanoparticular liposome (Fig. 3). In addition, $\mathrm{PEG}_{30000}$-BSA activated complement system presumably was mediated by anti-PEG IgM elicited by a previous dose (Fig. 4). Taken together, these results suggest that the administration of 1 PEGylated substance may accelerate the clearance of subsequent doses of the same PEGylated substance or another PEGylated substance, resulting in a reduced therapeutic efficacy of the PEGylated derivative. This would be another problem for PEGylation, which was originally expected to increase the residence time of the substance in the body.

It is hard to define the region of PEG that is recognized by an anti-PEG IgM. Richter and Akerblom ${ }^{27}$ ) proposed in an earlier study that the antigenic determinant of PEG may be a sequence of 6-7 $-\mathrm{CH}_{2} \mathrm{CH}_{2} \mathrm{O}$-units. Roffler and co-workers ${ }^{35,36}$ demonstrated that the monoclonal anti-PEG $\operatorname{IgM}$ generated by antibody-PEG-modified $\beta \mathrm{G}$ recognizes the repeating sequence (16 $-\mathrm{CH}_{2} \mathrm{CH}_{2} \mathrm{O}$-units) of PEG. Thus, the anti-PEG $\operatorname{IgM}$ described in the present study may bind to the repeating sequence $\left(-\mathrm{CH}_{2} \mathrm{CH}_{2} \mathrm{O}\right.$-units) of PEG.
Consistent with our earlier observations for PEGylated liposomes, ${ }^{37)}$ following the intravenous injection with PEGylated proteins, anti-PEG IgM level began to increase at day 3, reached the maximum at day 5 , and then decreased gradually (Fig. 1). In addition, a splenectomy study indicated that the spleen is responsible for promoting the anti-PEG IgM production elicited by the intravenous injection of PEG-BSA as well as PEGylated liposome (Fig. 3). These results indicate that, like PEGylated liposomes, PEGylated proteins may promote an immune response against PEG. We recently proposed that PEG on the PEGylated liposome stimulates the immune system as one of the TI antigens, ${ }^{37,38)}$ such as bacterial polysaccharide and polyvinyl pyrrolidone. ${ }^{39)}$ Once the PEGylated proteins reach the spleen, they may bind and crosslink to anti-PEG IgM expressed on the surface of B cells, and consequently trigger the production of an anti-PEG IgM. With respect to PEGylated liposome, we showed that lipid dose for injection is one of crucial factors to determine the level of anti-PEG IgM induction; the higher the dose the smaller the anti-PEG IgM induction. ${ }^{40)}$ At low amounts of PEGylated protein in spleen the level of crosslinking with B cells might be sufficient to activate the cells specifically; at high amounts of PEGylated protein the cells might rather become anergic. Hence, it is presumed that the physicochemical properties of PEGylated proteins, such as PEG chain length, numbers of the PEG branch and the PEG modification ratio, strongly affect the pharmacokinetics and interactions with $\mathrm{B}$ cells and are crucial to determining the degree of anti-PEG IgM production elicited by PEGylated proteins (Fig. 1).

Nakagawa and co-workers reported that, as a result of higher tumor accumulation rates and transgene expression in tumors, the systemic administration of PEG-Ad has a potential for systemic cancer gene therapy that is greater than that of unmodified Ad due to the EPR effect. ${ }^{15-18)}$ In addition, they showed that the PEGylation to Ad can avoid production of specific neutralizing Abs to Ad following intravenous administration. ${ }^{17)}$ However, in the present study, we observed that a single intravenous injection of PEG-Ad elicits anti-PEG IgM, although neutralizing anti-Ad Abs were not detected (Fig. 5). Such anti-PEG IgM would enhance elimination of PEG-Ad from blood circulation and consequently suppress the therapeutic effect of PEG-Ad by attenuating the level of transgene expression. The relationship between the production of antiPEG IgM and the therapeutic efficacy of PEG-Ad in therapy after repeated administration remains unclear and should be the subject of future investigation.

\section{CONCLUSION}

The results of the present study clearly indicate that anti-PEG IgM can be produced and may limit the efficacy of PEGylated substances such as proteins, Ad vector, and particles in some patients. The immunogenicity of PEGylated substances is usually tested directly against the primary substances, rather than against covalently attached PEG. Our study suggests that the PEG immunogenicity of PEGylated therapeutic agents and particles deserves further investigation.

Acknowledgements The authors thank Mr. James L. McDonald for his helpful advice in developing the English manuscript. This work was supported in part by a Grant-in-Aid 
for Scientific Research (B) (23390012) from the Ministry of Education, Culture, Sports, Science and Technology of Japan.

\section{REFERENCES}

1) Werle M, Bernkop-Schnürch A. Strategies to improve plasma half life time of peptide and protein drugs. Amino Acids, 30, 351-367 (2006).

2) Constantinou A, Chen C, Deonarain MP. Modulating the pharmacokinetics of therapeutic antibodies. Biotechnol. Lett., 32, 609-622 (2010).

3) $\mathrm{Xu} \mathrm{L}$, Anchordoquy T. Drug delivery trends in clinical trials and translational medicine: challenges and opportunities in the delivery of nucleic acid-based therapeutics. J. Pharm. Sci., 100, 38-52 (2011).

4) Roberts MJ, Bentley MD, Harris JM. Chemistry for peptide and protein PEGylation. Adv. Drug Deliv. Rev., 54, 459-476 (2002).

5) Zalipsky S. Functionalized poly(ethylene glycol) for preparation of biologically relevant conjugates. Bioconjug. Chem., 6, 150-165 (1995).

6) Harris JM, Chess RB. Effect of pegylation on pharmaceuticals. Nat. Rev. Drug Discov., 2, 214-221 (2003).

7) Caliceti P, Veronese FM. Pharmacokinetic and biodistribution properties of poly(ethylene glycol)-protein conjugates. Adv. Drug Deliv. Rev., 55, 1261-1277 (2003).

8) Sun X, Yang Z, Li S, Tan Y, Zhang N, Wang X, Yagi S, Yoshioka T, Takimoto A, Mitsushima K, Suginaka A, Frenkel EP, Hoffman RM. In vivo efficacy of recombinant methioninase is enhanced by the combination of polyethylene glycol conjugation and pyridoxal 5'-phosphate supplementation. Cancer Res., 63, 8377-8383 (2003).

9) Veronese FM, Pasut G. PEGylation, successful approach to drug delivery. Drug Discov. Today, 10, 1451-1458 (2005).

10) Wonganan P, Croyle MA. PEGylated adenoviruses: From mice to monkeys. Viruses, 2, 468-502 (2010).

11) Papahadjopoulos D, Allen TM, Gabizon A, Mayhew E, Matthay K, Huang SK, Lee KD, Woodle MC, Lasic DD, Redemann C, et al. Sterically stabilized liposomes: improvements in pharmacokinetics and antitumor therapeutic efficacy. Proc. Natl. Acad. Sci. U.S.A., 88, 11460-11464 (1991).

12) Maeda H, Matsumura Y. EPR effect based drug design and clinical outlook for enhanced cancer chemotherapy. Adv. Drug Deliv. Rev., 63, 129-130 (2011).

13) Krown SE, Northfelt DW, Osoba D, Stewart JS. Use of liposomal anthracyclines in Kaposi's sarcoma. Semin. Oncol., 31 (Suppl. 13), 36-52 (2004)

14) Coleman RE, Biganzoli L, Canney P, Dirix L, Mauriac L, Chollet P, Batter V, Ngalula-Kabanga E, Dittrich C, Piccart M. A randomised phase II study of two different schedules of pegylated liposomal doxorubicin in metastatic breast cancer (EORTC-10993). Eur. J. Cancer, 42, 882-887 (2006).

15) Gao JQ, Eto Y, Yoshioka Y, Sekiguchi F, Kurachi S, Morishige T, Yao X, Watanabe H, Asavatanabodee R, Sakurai F, Mizuguchi H, Okada Y, Mukai Y, Tsutsumi Y, Mayumi T, Okada N, Nakagawa $\mathrm{S}$. Effective tumor targeted gene transfer using PEGylated adenovirus vector via systemic administration. J. Control. Release, 122, 102-110 (2007).

16) Yao X, Yoshioka Y, Morishige T, Eto Y, Watanabe H, Okada Y, Mizuguchi H, Mukai Y, Okada N, Nakagawa S. Systemic administration of a PEGylated adenovirus vector with a cancer-specific promoter is effective in a mouse model of metastasis. Gene Ther., 16, 1395-1404 (2009).

17) Eto $Y$, Yoshioka $Y$, Ishida $T$, Yao $X$, Morishige $T$, Narimatsu S, Mizuguchi H, Mukai Y, Okada N, Kiwada H, Nakagawa S. Optimized PEGylated adenovirus vector reduces the anti-vector humoral immune response against adenovirus and induces a therapeutic effect against metastatic lung cancer. Biol. Pharm. Bull., 33,
1540-1544 (2010).

18) Yao X, Yoshioka Y, Morishige T, Eto Y, Narimatsu S, Kawai Y, Mizuguchi H, Gao JQ, Mukai Y, Okada N, Nakagawa S. Tumor vascular targeted delivery of polymer-conjugated adenovirus vector for cancer gene therapy. Mol. Ther., 19, 1619-1625 (2011).

19) Dams ET, Laverman P, Oyen WJ, Storm G, Scherphof GL, van Der Meer JW, Corstens FH, Boerman OC. Accelerated blood clearance and altered biodistribution of repeated injections of sterically stabilized liposomes. J. Pharmacol. Exp. Ther., 292, 1071-1079 (2000).

20) Ishida $T$, Maeda R, Ichihara M, Irimura K, Kiwada H. Accelerated clearance of PEGylated liposomes in rats after repeated injections. J. Control. Release, 88, 35-42 (2003).

21) Ishida $T$, Ichihara $M$, Wang $X$, Kiwada H. Spleen plays an important role in the induction of accelerated blood clearance of PEGylated liposomes. J. Control. Release, 115, 243-250 (2006).

22) Ishida $T$, Ichihara M, Wang $X$, Yamamoto $K$, Kimura J, Majima E, Kiwada H. Injection of PEGylated liposomes in rats elicits PEGspecific IgM, which is responsible for rapid elimination of a second dose of PEGylated liposomes. J. Control. Release, 112, 15-25 (2006).

23) Bartlett GR. Colorimetric assay methods for free and phosphorylated glyceric acids. J. Biol. Chem., 234, 469-471 (1959).

24) Mizuguchi H, Kay MA. A simple method for constructing E1- and E1/E4-deleted recombinant adenoviral vectors. Hum. Gene Ther., 10, 2013-2017 (1999).

25) Mizuguchi H, Kay MA. Efficient construction of a recombinant adenovirus vector by an improved in vitro ligation method. Hum. Gene Ther., 9, 2577-2583 (1998).

26) Jevsevar S, Kunstelj M, Porekar VG. PEGylation of therapeutic proteins. Biotechnol. J., 5, 113-128 (2010).

27) Richter AW, Akerblom E. Antibodies against polyethylene glycol produced in animals by immunization with monomethoxy polyethylene glycol modified proteins. Int. Arch. Allergy Appl. Immunol., 70, 124-131 (1983).

28) Ganson NJ, Kelly SJ, Scarlett E, Sundy JS, Hershfield MS. Control of hyperuricemia in subjects with refractory gout, and induction of antibody against poly(ethylene glycol) (PEG), in a phase I trial of subcutaneous PEGylated urate oxidase. Arthritis Res. Ther., 8, R12 (2006).

29) Armstrong JK, Hempel G, Koling S, Chan LS, Fisher T, Meiselman HJ, Garratty G. Antibody against poly(ethylene glycol) adversely affects PEG-asparaginase therapy in acute lymphoblastic leukemia patients. Cancer, 110, 103-111 (2007).

30) Rubin B. The immune response against hapten-autologous protein conjugates in the mouse. I. Specificity of antibodies produced during the primary response against dinitrophenylated mouse serum albumin. Eur. J. Immunol., 3, 26-32 (1973).

31) Klaus GG, Janossy G, Humphrey JH. The immunological properties of haptens coupled to thymus-independent carrier molecules. III. The role of the immunogenicity and mitogenicity of the carrier in the induction of primary IgM anti-hapten responses. Eur. J. Immunol., 5, 105-111 (1975).

32) Wang $X$, Ishida T, Kiwada $H$. Anti-PEG IgM elicited by injection of liposomes is involved in the enhanced blood clearance of a subsequent dose of PEGylated liposomes. J. Control. Release, 119, 236-244 (2007).

33) Ishihara T, Takeda M, Sakamoto H, Kimoto A, Kobayashi C, Takasaki N, Yuki K, Tanaka K, Takenaga M, Igarashi R, Maeda T, Yamakawa N, Okamoto Y, Otsuka M, Ishida T, Kiwada H, Mizushima Y, Mizushima T. Accelerated blood clearance phenomenon upon repeated injection of PEG-modified PLA-nanoparticles. Pharm. Res., 26, 2270-2279 (2009).

34) Kaminskas LM, McLeod VM, Porter CJ, Boyd BJ. Differences in colloidal structure of PEGylated nanomaterials dictate the likelihood of accelerated blood clearance. J. Pharm. Sci., 100, 5069-5077 (2011). 
35) Cheng TL, Chen BM, Chern JW, Wu MF, Roffler SR. Efficient clearance of poly(ethylene glycol)-modified immunoenzyme with anti-PEG monoclonal antibody for prodrug cancer therapy. Bioconjug. Chem., 11, 258-266 (2000).

36) Cheng TL, Wu PY, Wu MF, Chern JW, Roffler SR. Accelerated clearance of polyethylene glycol-modified proteins by anti-polyethylene glycol IgM. Bioconjug. Chem., 10, 520-528 (1999).

37) Ishida $T$, Wang $X$, Shimizu $T$, Nawata K, Kiwada H. PEGylated liposomes elicit an anti-PEG IgM response in a $\mathrm{T}$ cell-independent manner. J. Control. Release, 122, 349-355 (2007).

38) Koide $H$, Asai $T$, Hatanaka $K$, Akai $S$, Ishii $T$, Kenjo E, Ishida $T$,
Kiwada H, Tsukada H, Oku N. T cell-independent B cell response is responsible for $\mathrm{ABC}$ phenomenon induced by repeated injection of PEGylated liposomes. Int. J. Pharm., 392, 218-223 (2010).

39) Bondada S, Wu H, Robertson DA, Chelvarajan RL. Accessory cell defect in unresponsiveness of neonates and aged to polysaccharide vaccines. Vaccine, 19, 557-565 (2000).

40) Ishida T, Atobe K, Wang X, Kiwada H. Accelerated blood clearance of PEGylated liposomes upon repeated injections: effect of doxorubicin-encapsulation and high-dose first injection. J. Control. Release, 115, 251-258 (2006). 